\title{
Experimental Analysis of Four Stroke Diesel Engine by using Carbon Nano Tubes Based Nano Fluids as a Coolant
}

\author{
M. Muruganandam ${ }^{1 \dagger}$ and P. C. Mukesh Kumar ${ }^{2}$ \\ ${ }^{1}$ Department of Mechanical Engineering, St. Joseph's College of Engineering and Technology, Thanjavur- \\ 613403, Tamilnadu, India \\ ${ }^{2}$ Department of Mechanical Engineering, University College of Engineering, Dindigul-624622. \\ Tamilnadu, India.
}

†Corresponding Author Email: CorrespondingAuthor@academic.edu

(Received February16, 2017; accepted July 30, 2017)

\begin{abstract}
The exciting coolants have reached their limitations of heat dissipating capacity. It is studied from the literature review that nanofluids are the novel and alternate heat transfer medium with significant temperature-dependent thermal conductivity even at very low particle concentrations than the conventional heat transfer fluids. In this experimental investigation, the multi walled carbon nanotube (MWCNT) water is used as a coolant in four stroke single cylinder diesel engine to assess the performance of the engine. The MWCNT/ water nanofluid is prepared with surfactant to get the stable suspension of nanofluid. Tests are performed by constant the mass flow rate $330 \mathrm{LPH}$ of coolant nanofluids and by changing the load and by keeping the speed constant. It is found that the brake thermal efficiency increases by 10 to $15 \%$, exhaust temperature decreases by 8 to $10 \%$ decreases and the specific fuel consumption decreases when compared to water as a coolant at the same testing condition.
\end{abstract}

Keywords: Nanofluid; Thermal conductivity; Coolant; Mass flow; Brake thermal efficiency.

\section{NOMENCLATURE}

$\begin{array}{ll}\text { A } & \text { heat transfer area } \\ \text { C } & \text { specific heat } \\ \text { h } & \text { heat transfer coefficient } \\ \text { k } & \text { thermal conductivity } \\ \text { m } & \text { mass flow rate }\end{array}$

\section{INTRODUCTION}

The cooling system of a four stroke diesel engine is important in maintaining its performance. The engine produces a lot of heat that must be removed in order for it to function optimally. The present cooling system that is available uses water and antifreezing agent as the coolant for the radiator to remove the heat from the engine via conduction and convection. The heat transfer performance of the coolant is not adequate to remove more heat that may be produced in the engine. With the use of nano particles, the surface area of heat transfer of coolant can be increased, thus increasing the heat transfer performance of the coolant. However, the concentration of the nano particles of MWCNT as

$\begin{array}{lll}\mathrm{Q} & \text { heat transfer rate } & \\ \mathrm{T} & \text { temperature } & \\ \mu & \text { dynamic viscosity } & \\ \Phi & \text { particle volume } & \text { concentration }\end{array}$

shown Fig. (1) can optimally transfer heat must be determined.

Heat transfer directly affects the engine performance, fuel efficiency, materials selection, and emission. The benefits of improved heat exchangers and heat transfer devices using nanofluids are as follows: reduced weight, which will improve fuel economy; smaller components, which take up less room under the hood and allow for greater latitude in aerodynamic styling; more effective cooling, and increased component life. Additionally, mining activities will be lower as less metal is required, minimizing the environmental impact and saving energy in metal production. Teng (2013) found that by reducing the size solid waste disposal problem is diminished at the end of the useful life cycle of heat 
transfer systems. Saidura (201) presented that nano coolant of MWCNT has a higher heat exchange capacity and efficiency than EG/W. Thermal conductivity of nano fluids with MWCNT can be increased up to $150 \%$. Several studies have been reported on the thermo-physical properties of CNT based nanofluids and show a considerable effect compared to the base fluid, as reviewed by Philip and Shima (2012). This enhancement is mainly governed by the volume fraction in nano tubes and the temperature. Ding (2006) found that thermal conductivity of CNT based nanofluid increases significantly with the temperature by $15 \%$ at $20^{\circ} \mathrm{C}$, $30 \%$ at $25^{\circ} \mathrm{C}$ and by $79 \%$ at $40^{\circ} \mathrm{C}$ at the same volume fraction. Meng (2012) showed that the relative thermal conductivity of CNT based nanofluid is independent of temperature for temperature range from 15 to $55^{\circ} \mathrm{C}$. These results are consistent with those found by $\mathrm{Yu}$ (2003) and Chen (2008). The effect of surfactant, aspect ratio of nanotubes, and the presence of nano clusters on thermal conductivity of CNT nanofluids were also investigated by Wen (2004), Assael (2005), Yand (2006), Garg (2009), Nasiri (2011) and Phuoc (2011).

The nano particles used in nanofluids are usually metals, oxides, carbides or carbon nano tubes as shown by Hassani (2015). Recent studies show that a radiator that is able to withstand higher thermal load could reduce the size of the radiator by approximately $30 \%$. Furthermore Peyghambarzadeh (2013) identified, the drag force, fuel pumping and fan power could be reduced as well, resulting in $10 \%$ fuel savings. Elias (2014) studied the thermosphysical properties of $\mathrm{Al} 2 \mathrm{O} 3$ nano particles suspended in car radiator coolant and found that the maximum enhancement of the nanofluid was $8.3 \%$ with the use of $1 \%$ concentration of nano particles at $50^{\circ} \mathrm{C}$. Raja (2013) investigated the performance of alumina water at different ranges of nano particles volume fractions. They concluded that the maximum heat transfer enhancement of heat transfer coefficient was $25 \%$ at 2 vol. \% of alumina nano particles.

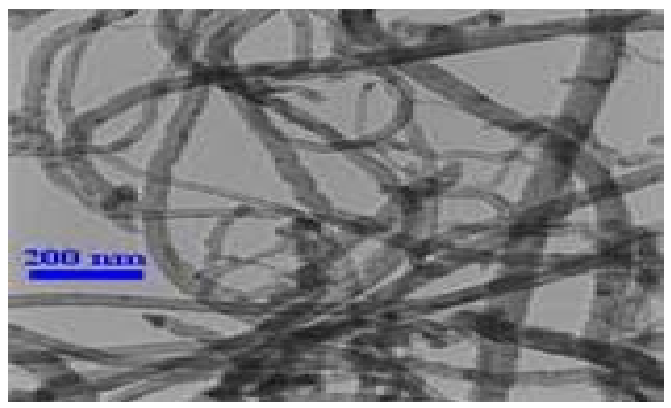

Fig. 1. SEM micrograph of MWCNT.

\section{PREPARATION OF MWCNT/ WATER NANOFLUID}

Preparation of Nano fluids is the first foot-step to the experimental studies of Nano fluids as pointed by Godson (2010). The two primary methods to prepare Nano fluids are single-step preparation process and the two-step preparation process. The one- step technique simultaneously makes and disperses the nanoparticles directly into a base fluid. This technique ensures stable dispersion and no agglomeration. In the two-step technique nanoparticles are produced by one of the physical or chemical synthesis techniques and proceed to disperse them into a base fluid. In the investigation by Hwang (2007), nano fluids were prepared by using Multi walled Carbon Nano Tube (MWCNT) with Distilled water, as base fluids at the volume concentration of $0.1 \%$ and with adding Sodium dodecyle butane sulfonate (SDBS) stabilizing agent. Two-step preparation process was used to prepare above nanofluids. In the study of Hiemenz (1986) and Prasher (2006), the required amount of base fluid was first poured into 1 liter glass bottle and mixed with MWCNT of $1 \% \mathrm{vol}$. concentration and the suspensions were dispersed using a magnetic stirrer. The homogeneous solutions were obtained after magnetic stirring as shown in Fig.2.

The magnetic stirrer employs a rotating magnetic field which stirs the magnetic pellet immersed in a fluid thus allowing it to spin very quickly which in turn enabling the even dispersion of the particles and ultrasonic vibrator (Toshiba, India) generating ultrasonic pulses of $40 \mathrm{~W}$ at $36 \pm 3 \mathrm{kHz}$ also ensures dispersion of particles in the fluid.

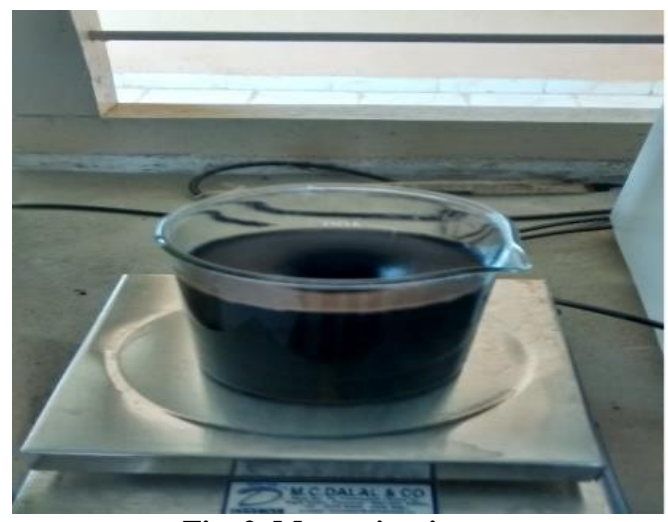

Fig. 2. Magnetic stirrer.

Sonication is a process in which sound waves are used to agitate particles in solution. Such disruptions can be used to mix solutions, speed the dissolution of a solid into a liquid (like sugar into water), and remove dissolved gas from liquids. To get a uniform dispersion and stable suspension which determine the final properties of nanofluids, the nanofluids are kept under ultrasonic bath (Fig.3) continuously for 3 hour with maintained at $40^{\circ} \mathrm{C}$.

\section{EXPERIMENTAL SETUP}

Figure4 shows the schematic photograph of experimental set up. The set up is four stroke diesel engines with alternator generator. This is consists of storage vessels with valve to control 
the flow on tube, magnet pump, flow meter, car radiator, connected with plastic hose. The engine cooling water inlet $\left(\mathrm{T}_{\text {in }}\right)$ and hot water outlet $\left(\mathrm{T}_{\text {out }}\right)$ is connected with car radiator. Hot water Inlet and cold water out let of the radiator temperatures measure with help of thermocouple. The output of radiator cooling water is store in the reservoir with help of magnet pump. The dimensions of from the test section are: the engine four stroke (Kirloskar) $5 \mathrm{HP}$, connected Tube inner diameter $\left(\mathrm{d}_{\mathrm{i}}\right) 12.7 \mathrm{~mm}$, outer diameter $\left(\mathrm{d}_{\mathrm{o}}\right) 13 \mathrm{~mm}$, magnet pump is $(330$ LPH), with Maruthi 800 car radiator.

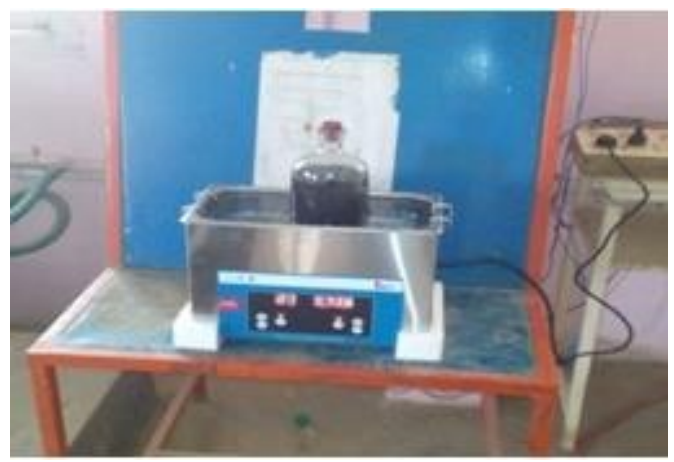

Fig. 3. Ultrasonic bath.

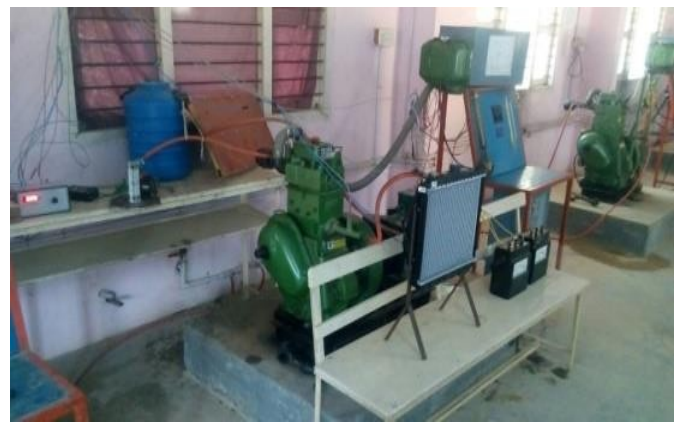

Fig. 4. Experimental set-up Photograph.

\subsection{Experimental Procedure}

Water is circulated to test the leakage, the function of thermocouples, $\mathrm{U}$ tube manometer and thermostat checked. Cold water is allowed to cooling water jacket and the pump is switched on continuous water Circulation. Know engine is started with maximum speed of $1500 \mathrm{rpm}$ no load conditions .The corresponding temperature are recorded with help of thermocouples. Similarly nanofluids at $0.1 \%$ volume concentration are circulated through the engine water jacket. Flow rate of water and nanofluids is kept constant ((330 LPH) and flow rate on tube side. The temperatures are measured during before attaining the steady state. After half an hour constant temperature is maintained at $39^{\circ} \mathrm{C}$. After that varying different load conditions like No load, 500W, $1000 \mathrm{~W}, 1500 \mathrm{~W}, 2000 \mathrm{~W}$. The thermal conductivity of MWCNT measured respectively.

\subsection{Estimation of Nanofluid Thermo- Physical Properties}

Thermo physical properties of nanofluids: effect of nano particle volume fraction and temperature the linear dependence of thermal conductivity enhancement of nanofluids can be simply related to nano particle volume fraction by the following empirical-model developed by Prasher (2006)

$\frac{k_{n f}}{k_{b f}}=1+C_{k} \phi$.

Where $\mathrm{Ck}$ is thermal conductivity enhancement coefficient's is here evaluated to 41,70 and 85 at $20^{\circ} \mathrm{C}, 30^{\circ} \mathrm{C}$ and $40^{\circ} \mathrm{Crespectively.}$

Maxwell model (1891) was used to determine thermal conductivity of the nano fluid:

$K_{\text {eff }}=\frac{K_{D}+2 K_{r}+2\left(K_{D}-K_{r}\right) \phi}{K_{D}+2 K_{r}-\left(K_{D}-K_{r}\right) \phi}$

Hamilton-Crosser model (1962) as expressed below was also used to measure thermal conductivity of the nanofluid:

$$
K e f f=\frac{K p(n-1) K f-2(n-1) \phi(K f-K p)}{K p(n-1) K f+\phi(K f-K p)} K f
$$

The model of Pak and Cho (1998) was used to be compared with the obtained experimental densities of the nanofluids using

The following equation of Xuan and Roetzel (2000) has been used to compare the experimental values of this

$\rho_{n f}=(1-\phi) \rho_{f}+\rho_{p}$

study

Where, $\mathrm{Cp}$ is the specific heat of nanofluids, is the density of nanofluid, and $\varnothing$ is the volume fraction of nano particles. Also $\mathrm{n}_{\mathrm{f}}, \mathrm{f}$, and s refer to

$C p, n f=\frac{(1-\phi) \rho f c p, f+\phi \rho c p, p}{\rho n f} \ldots \ldots \ldots \ldots \ldots . .$.

nanofluid, fluid, and solid respectively.

\subsection{Data Processing}

Heat transfer rate from cold fluid to hot fluid can be easily calculated from the measured temperature change, flow rate and the specific heat of a fluid.

$Q_{w}=m_{w} C_{w}\left(T_{w o}-T_{w i}\right)$

$Q_{n}=m_{n} C_{n}\left(T_{n o}-T_{n i}\right)$.

where $\mathrm{Q}_{\mathrm{w}}$ and $\mathrm{Q}_{\mathrm{n}}$ are the heat transfer rates of water and with thermocouples.

Nano fluid, $m_{n}$ is the mass flow rate of water, $C_{n}$ is the heat capacity of nanofluid, $T_{n i}$ and $T_{n o}$ are the temperatures of nanofluid inlet and exit of 
the water jacket of the engine.

\section{RESULTS AND DISCUSSION}

\subsection{Exhaust Temperature}

In this experimental work, when compared to water, the exhaust temperature is $10-15 \%$ decreases in nano fluid as shown in Fig.5.

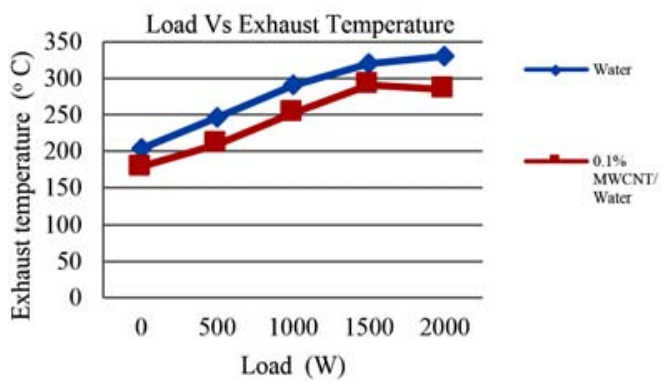

Fig. 5. Effect of load on exhaust temperature.

\subsection{Specific Fuel Consumption}

Figure 6 illustrates the effect of load on specific fuel consumption. When the load increases, the specific fuel consumption is decreases for nano fluid.

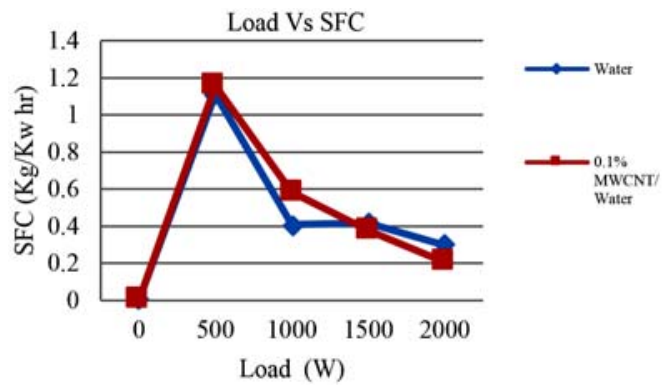

Fig. 6. Effect of load on specific fuel consumption.

\subsection{Brake Thermal Efficiency}

Figure 7 shows the effect of load on brake thermal efficiency. The brake thermal efficiency is gradually increases for nano fluid, when compared to water.

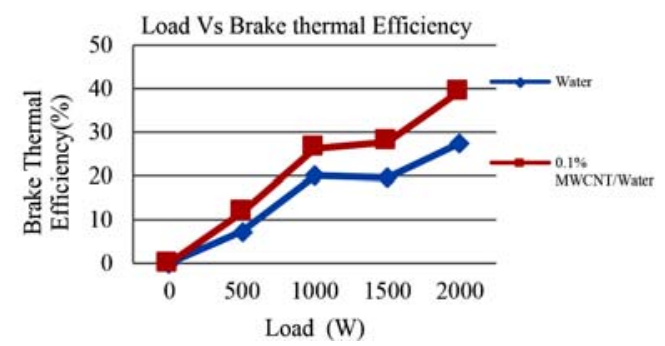

Fig.7 Effect of load on brake thermal efficiency.

\section{CONCLUSION}

In this paper, Experimental analysis of four stroke diesel engine handling carbon nanotube based nanofluids at $0.1 \%$ particle volume concentration were tested. The performance of nanofluids has been compared with water. Following observations were made from the investigations.

(i) Exhaust temperature decreases by 8 to $10 \%$.

(ii) Specific fuel consumption decreases at high load condition

(iii) Brake thermal efficiency gradually increases by 10 to $15 \%$ than water.

Further work is needed to observe the $0.3 \%$, and $0.5 \%$ vol MWCNT concentrations.

\section{REFERENCES}

Assael, M. J., I. N. Mataxa, J. Arvanitidis, D. Christophilos and C. Lioutas (2005). Thermal conductivity enhancement in aqueous suspensions of carbon multi-walled and double-walled nanotubes in the presence of two different dispersants, Int.J. Thermo phys. 26, 647-664.

Chen, L., H. Xie, Y. Li and W. Yu (2008). Nanofluids containing carbon nanotubes treated by mechanochemical reaction, Thermochim. Acta 477, 4-21.

Ding, Y., H. Alias, D. Wen and R. A. Williams (2006). Heat transfer of aqueous suspensions of carbon nanotubes (CNT nanofluids), Int. J. Heat Mass Transfer 49, 240-250.

Elias, M. M., I. M. Mahbubul, R. Saidur, M. R. Sohel, I. M. Shahru, S. S. Khaleduzzaman and S. Sadeghipour (2014). Experimental investigation on the thermo-physical properties ofA12O3 nanoparticles suspended in car radiator coolant, International Communications in Heat and Mass Transfer 54, 48-53.

Garg, P., L. A. Jorge, C. Marsh, T. A. Carlson, D. A. Kessler and K. Annamalai (2009). An experimental study on the effect of ultrasonication on viscosity and heat transfer performance of multi-wall carbon nanotubebased aqueous nanofluids, Int. J. Heat Mass Transfer 52, 5090-5101.

Godson, L., D. M. Lal and S. Wong wises (2010). Measurement of thermo physical properties of metallic nanofluids for high temperature applications, Nanoscale and micro scale thermo physical engineering 14(3), 152-173.

Hamilton, R. L. and O. K. Crosser (1962). Thermal conductivity of heterogeneous two-component systems, Ind. Eng. Chem. Fundam. 1 (3) 187191.

Hassani, S., R. Saidur, S. Mekhilef and A. Hepbasli (2015). A new correlation for predicting the thermal conductivity of nanofluids; using dimensional analysis, International Journal of Heat and Mass Transfer 90, 121-130. 
Hiemenz, P. C.and M. Dekker (1986). Principles of colloid and surface chemistry, Second ed., Dekker, New York.

Hwang, Y., J. K. Lee, C. H. Lee, Y. M. Jung, S. I. Cheong, C. G. Lee, B. C. Ku and S. P. Jang (2007). Stability and thermal conductivity characteristics of nanofluids, Thermo chim. Acta 455(1-2), 70-74.

Maxwell, J. (1891). A Treatise on Electricity and Magnetisms, Chap 9, Art 310-314, 1, Clarendon Press, Oxford,.

Meng, Z., D. Wu, L. Wang, H. Zhu and Q. Li (2012). Carbon nanotube glycol nanofluid: photothermal properties, thermal conductivities and rheological behavior, Particuology 10, 614-618.

Nasiri, A., M. Shariaty Niasar, A. Rashidi, A. Amrollahi and R. Khodafarin (2011). Effect of dispersion method on thermal conductivity and stability of nanofluid, Exp. Therm. Fluid Sci. 35, 717-723.

Pak, B. C. and Y. I. Cho (1998). Hydrodynamic and heat transfer study of dispersed fluids with Submicron metallic oxide particles, Exp. Heat Transf. 11 (2) 151-170.

Peyghambarzadeh, S. M., S. H. Hashemabadi, M. Naraki and Y. Vermahmoudi (2013). Experimental study of overall heat transfer coefficient in the application of dilute nanofluids in the car radiator, Applied Thermal Engineering 52, 8-16,

Philip, J. and P. D. Shima (2012). Thermal properties of nanofluids, Adv. Colloid Interface Sci. 183-184, 30-45.

Phuoc, T. X., M. Massoudi and R. H. Chen (2011). Viscosity and thermal conductivity of nanofluids containing carbon nanotubes stabilized by chitosan, Int. J. Therm. Sci. 50, 12-18.

Prasher, R., D. Song, J. Wang and P. Phelan, (2006). Measurements of nanofluid viscosity and its implications for thermal applications, Appl. Phys. Lett. 89, 133108.

Raja, R. V. M., S. Suresh and R. Vivekananthan (2013). Effects of heat transfer enhancement and NOx emission using A12O3/water nanofluid as coolant in CI engine", Indian Journal of Engineering and Materials Sciences $20,7$.

Roetzel, Y. X. (2000). Conceptions for heat transfer correlation of nanofluids, International Journal of Heat and Mass Transfer 43(19), 3701-3707.

Saidura, R., K. Y. Leong and H. A. Mohammad (2011). A review on applications and challenges of nano fluids, Renewable and Sustainable Energy Reviews 15, 1646-1668

Teng, T. P. and C. C. Yu (2013). Heat dissipation performance MWCNT of MWCN/WT satnerano-coolant for vehicle, Experimental Thermal and Fluid Science 49, 22-30

Wen, D. S. and Y. L. Ding (2004). Effective thermal conductivity of aqueous suspensions of carbon nanotubes (nanofluids), J.Thermophys. Heat Transfer 18, 481-485.

Yang, Y., E. A. Grulke, Z. G. Zhanh and G. Wu (2006). Thermal and rheological properties of carbon nanotube-in-oil dispersions, J. Appl. Phys. 99, 114307.

$\mathrm{Yu}, \mathrm{W}$. and S. U. S. Choi (2003). The role of interfacial layers in the enhanced thermal conductivity of nanofluids: a renovated Maxwell model, J. Nanoparticle Res. 5, 167171. 